\title{
ACADEMIC PAPER TITLES AND THEIR DOMINATING PATTERNS: A RUSSIAN-ENGLISH PERSPECTIVE ${ }^{1}$
}

\author{
Nadezhda K. Ryabtseva \\ Institute of Linguistics, Russian Academy of Sciences, Moscow, Russia
}

\begin{abstract}
The article shows the key role that academic paper titles play in presenting paper contents and burden, and demonstrates cultural and linguistic differences between the academic style in Russian and in English. The author explains the way the academic style is connected with language's grammatical structure and its culturespecific communicative patterns, and illustrates that the prevailing paper titles' patterns are predetermined by academic style dominants in a particular language.

The fundamental difference in paper titles organization in Russian and English academic style is that in Russian the prevailing pattern in naming a paper has traditionally been an extended single noun group with several prepositional and postpositional subordinates, predominantly in Genitive. In English, on the contrary, the title in most cases consists in two parts connected by a column, full stop, conjunction or a preposition. That is why there is a communicative asymmetry in academic paper titles' verbalization principles in Russian and in English, as these principles are mostly language specific and have their own dominating linguistic patterns. It is also explicated that there is an asymmetry between academic paper titles in Russian and in English not only in their structure and organization, but in lexicon as well. That is why paper titles translated word-for-word from Russian into English often fail to map standard stylistic patterns characteristic to academic English. There are some comments as well on a rather new pattern in titling academic papers across languages. It has to do with using various expressive stylistic means, which never fail to attract peers' attention. There are also some comments on using "translator's false friends" in rendering academic paper titles from Russian into English, particularly by native Russian speakers.
\end{abstract}

The research is based on extensive linguistic corpus data (10 000 paper titles authored by native Russian and English speakers), has practical implications and guidelines, as well as proposes some topical theoretical interpretations concerning its subject matter.

Key words: academic English, academic Russian, scientific paper titles, crosslinguistic asymmetry, languagespecific communicative patterns, 'attention attracting titles'.

Citation. Ryabtseva N.K. Academic Paper Titles and Their Dominating Patterns: a Russian-English Perspective. Vestnik Volgogradskogo gosudarstvennogo universiteta. Seriya 2, Yazykoznanie [Science Journal of Volgograd State University. Linguistics], 2018, vol. 17, no. 2, pp. 33-43. (in Russian). DOI: https://doi.org/10.15688/jvolsu2.2018.2.4

\section{НАЗВАНИЕ КАК ДОМИНАНТНЫЙ КОМПОНЕНТ НАУЧНОГО ТЕКСТА: РУССКО-АНГЛИЙСКИЕ МЕЖЪЯЗЫКОВЫЕ «НЕСООТВЕТСТВИЯ»}

\author{
Надежда Константиновна Рябцева \\ Институт языкознания РАН, г. Москва, Россия
}

Аннотация. В статье показана ключевая роль названия научного текста в отражении его содержания и предназначения. Указаны культурно и лингвистически обусловленные различия в научной речи на русском и английском языках, а также связь научного стиля со строением языка и доминирующими в нем моделями названий научных текстов.

На основе анализа специально созданного представительного лингвистического корпуса названий современных аутентичных научных текстов на русском и английском языках (1980-2017 гг.) объемом свыше 
10 тыс. вхождений продемонстрирована зависимость структуры названий научных произведений от сложившихся стилистических доминант научной речи на данных языках. Показаны сходства и различия в принципах организации названий научных произведений, преобладающих в русском и английском языках и выявлены недостатки пословного перевода названий с русского языка на английский. Охарактеризованы особенности использования «экспрессивно маркированных» названий - нового для научной речи типа заголовков, получивших международное распространение и признание благодаря их «аттрактивной» силе.

В качестве важных результатов исследования в статье кратко сформулированы принципы перевода названий научных статей с русского языка на английский и предложена теоретическая интерпретация объекта и предмета проведенного исследования с точки зрения когнитивной лингвистики и «интегративного переводоведения».

Ключевые слова: научная речь, английский язык, русский язык, название научного произведения, межъязыковые «несоответствия», лингвоспецифичные коммуникативные доминанты, «аттрактивные названия».

Цитирование. Рябцева Н. К. Название как доминантный компонент научного текста: русско-английские межъязыковые «несоответствия» // Вестник Волгоградского государственного университета. Серия 2, Языкознание. - 2018. - Т. 17, № 2. - C. 33-43. - DOI: https://doi.org/10.15688/jvolsu2.2018.2.4

\section{Исходные положения}

Название научной статьи, книги или доклада в свернутом виде отражает чаще всего не только их содержание, но и научный стиль мышления носителя языка, а также научный стиль речи, сложившийся в данном языке. По этой причине (а также по ряду других) название научного произведения, как и названия произведений других стилей и жанров, именно благодаря своей уникальной коммуникативной значимости и полифункциональности давно и постоянно привлекают внимание лингвистов разных специальностей и направлений: от грамматистов до когнитологов, от стилистов до интернет-аналитиков. В настоящее время можно говорить о растущей значимости названий текстов всех без исключения типов, особенно в связи с постоянно увеличивающимся потоком информации, «интернетизацией» коммуникации и ее «прагматизацией».

Далее будут рассмотрены основные коммуникативные и содержательные свойства заголовков; отличительные особенности научной речи на русском и английском языках, влияющие на формирование названий научных статей; язык и стиль научных заголовков на русском и английском языках в контрастивном аспекте, а также недостатки пословного перевода названий научных статей с русского на английский.

В исследовании используются корпусный, квантитативный, семантический, контрастивный и когнитивно-прагматический методы анализа языкового материала.

\section{Основные коммуникативные и содержательные свойства заголовка}

Заголовок - один из важнейших коммуникативно значимых элементов структурной организации любого, в том числе научного, текста [Бахтин, 1979; Костомаров, 1965; Котюрова, Баженова, 2007]; он имеет свои функциональные, стилистические, прагматические и другие характеристики. Так, заголовок выражает основную идею текста, идентифицирует, символизирует и «замещает» его, указывает его тему, призван привлечь к нему внимание адресата и направляет его, задает перспективу изложения и восприятия текста, вводит его в коммуникативное пространство и т. д. Кроме того, заголовок научного произведения представляет собой автосемантичное высказывание-суждение. Он может быть различной структуры и потому образует автономный речевой жанр, динамично развивающийся в современном научном дискурсе на любом языке. В ряде исследований подчеркивается, что названия научных произведений, в том числе на русском языке, эволюционируют и приобретают новые, не свойственные им ранее черты [Куликова, Салмина, 2015; Табанакова, 2016, с. 85-87].

Одним из характерных свойств названий научных статей выступает их непосредственная связь с особенностями научного стиля, сложившимися в данном языке, с одной стороны, и с особенностями грамматического строя данного языка, а также с доминирующими в нем прагматическими и 
коммуникативными установками - с другой. Например, в русском языке благодаря большому количеству словоизменительных категорий (род, число, склонение, спряжение) и свободному порядку слов имеется возможность строить предложения, распространенные большим количеством различных подчиненных компонентов, согласование между которыми может достигать нескольких уровней связности [Котюрова, 2016, c. 68]. В результате названия научных статей могут представлять собой развернутые и при этом единые многокомпонентные именные образования со сложной синтаксической структурой, ср.: «O принципе деления редуцированных гласных на сильные и слабые в позднем праславянском и древних славянских языках» («Вопросы языкознания»- ВЯ). Для английского языка подобные структуры не характерны. Кроме того, существуют и другие принципиально важные стилистические особенности научных текстов на русском и английском языках, находящие непосредственное отражение в структуре и организации названий научных произведений.

\section{Отличительные особенности} научной речи

\section{на английском и русском языках}

Отличительными особенностями научной (и не только) речи на английском языке являются в первую очередь ориентация на адресата, а потому ясность, точность, логичность и эксплицитность выражения мысли, краткость, компактность и «сжатость» изложения, прозрачность и четкость структуры и организации текста, преимущественное использование предметной и глагольной лексики, отказ от многосложных отглагольных и абстрактных существительных и др. В результате научный текст на английском языке синтаксически разворачивается преимущественно линейно, состоит из довольно коротких слов, выражений и предложений, эксплицитно соединенных ключевыми словами и логическими коннекторами, и потому достаточно легок для восприятия и понимания [Брежнева, 2017; McCarthy, O'Dell, 2012; Riabtseva, 2013; Swales, Feak, 2010; Wallwork, 2011].
Для научного текста на русском языке характерно использование большого количества абстрактной и отглагольной лексики, синтаксически сложных конструкций и оборотов, достаточно длинных предложений с «пересекающимися» синтаксическими связями и др. При этом понимание текста затрудняется, особенно ввиду использования формальных средств связности: местоименных и других грамматических показателей. При переводе таких текстов на английский язык «необходимо обращать внимание на возможность отступать от буквы исходного текста, чувствовать разумную свободу в использовании языка в процессе перевода: попытка переноса традиционного российского стиля научного повествования в другой языковой код приводит к тому, что в переводе вместо научности возникает ее суррогат, некая наукообразность» [Меньшакова, 2016, с. 112]. См. выделенные полужирным курсивом малоинформативные обороты и выделенные подчеркиванием стилистически неудачные повторы предлога во фрагменте аннотации (к статье из журнала): The paper is aimed at the research of the fundamental scientific problem of influence of Internet... (vs. The paper studies internet's influence...).

Указанные черты научного стиля отражаются на языке, форме и организации названий научных произведений на русском и английском языках.

\section{Язык и стиль научных заголовков на русском и английском языках: контрастивный аспект}

Специально созданный лингвистический корпус названий современных научных произведений (1980-2017 гг.) на английском и русском языках (авторы - носители языка) объемом свыше 10 тыс. вхождений позволил выявить следующие закономерности в их построении.

1. Сходство названий научных произведений на русском и английском языках ограничивается наличием только одной типичной для них обоих конструкции. Это короткое название - нераспространенная дополнительными компонентами именная группа, чаще всего с «не-генитивным» предлогом: «Надзнаковость языка», «О варьировании слов в не- 
мецком языке», «Место сванского в семье картвельских языков» (ВЯ) - Negation in Uralic Languages (John Benjamins - JBs 2015), Metaphors We Live By (Chicago 1980), The Axiological Parameter in Preconceptual Image Schemata (JBs 1993). Менее 8 \% названий в каждом из языков.

2. Для научной речи на русском языке наиболее распространенными и типичными являются следующие частично пересекающиеся модели:

- с использованием (двух и более) генитивных конструкций (свыше 19 \% названий): «Лингвистические проблемы упорядочения научно-технической терминологии", "Влияние сенсомоторных стереотипов на понимание пространственных конструкций» (ВЯ), «Военно-экономический аспект современного состояния начиональной безопасности России» (Вестник РГНФ);

- с использованием синтаксически развернутых именных групп с большим количеством препозитивных и постпозитивных по отношению к главному зависимых компонентов (с преобладанием генитивных конструкций) (до 33 \% названий): «Основные принциипы построения словарной статьи с заглавным словом - экзотизмом» (Научный доклад (на международной конференции) НД 2016), «Исследования морской арктической комплексной экспедиции на Белом море» (Вестник РГНФ). В подавляющем большинстве случаев (в научных журналах, материалах и программах конференций) такие названия переводятся с русского языка на английский пословно, ср. употребление «ofгенитива»: «Major Principles of the Structure of the Dictionary Entries for Exotic Words», "Research of Complex Arctic Sea Expedition in White Sea». При этом совершенно естественное для научной речи на русском языке название с генитивом, например: «Из истории становления дискретной математи$\boldsymbol{\kappa} \boldsymbol{u}\rangle$ при пословном переводе на английский превращается в противоестественное для английской (научной) речи многократное повторение предлога of (см. [Riabtseva, 1988]): «Out of History of Formation of Discreet Mathematics» (Вестник РГНФ);

- с использованием (часто в качестве первого компонента) слова с абстрактной и потому «неточной», широкой семантикой в комбинации с отглагольной лексикой (до 19 \% названий): (Основные) Принщипь (исследования), Методь (анализа), Проблемь (изучения), $K$ вопросу о (реконструкиии) и т. п. Например, для научной речи на русском языке являются вполне нейтральными такие названия, как «K проблеме типологии речи», "K вопросу о номинации в древнерусском языке», «О принципе деления редуцированных гласных на сильные и слабые в позднем праславянском и древних славянских языках» (ВЯ). Названия научных статей на английском языке с подобных выражений обычно не начинаются, такие конструкции в целом редко используются в научном заголовке, они как бы и так подразумеваются: Referencepoint Constructions (JBs 1993); Cyclic and Noncyclic Phonological Effects in a Declarative Grammar (JBs 1998); Spatial Language and Spatial Cognition (JBs 1995);

- с использованием различных металингвистических конструкций - дополнительных (пояснительных, уточняющих) комментариев, которые помещаются после названия в скобки (до $11 \%$ названий): (на материале иранских языков), (в связи с выходом в свет Русскояпонского словаря) (ВЯ), (на основе археологических данных) (Вестник РГНФ) и т. п. В английском языке, напротив, такие комментарии и модели названий крайне редки.

В корпусе представлены и другие модели названий (менее $9 \%$ всех названий): « $y_{c}$ тупительность как системообразующий смыслл», «Многозначные слова в контексте и вне контекста», «O стыде и стуже», «Союз если и семантические примитивы», "Актуально ли учение Марра?», «Язык, мылиление, культура», "Языковая метафора в словаре. Опыт системного описания», «Русский язык ищет артикль», "Дайте миру шанс! Словарь современных политических лозунгов России и Германии» (ВЯ).

3. Для названий научных статей на английском языке, помимо указанных выше моделей (с использованием «не-генитивных» конструкций, конструкций без предлога of), характерными являются следующие частично пересекающиеся модели:

- с сочинительным союзом (до $28 \%$ названий): Human and Machine Vision (New York 
1983); Force Dynamics in Language and Thought (Chicago 1985); Syntactic Categories and Grammatical Relations (Chicago 1991); Polysemy and Related Phenomena from a Cognitive Linguistic Viewpoint (Cambridge 1995);

- с двоеточием: Dictionary Typologies:

A Pragmatic Approach (НД 2015); From Etymology to Pragmatics: Metaphorical and Cultural Aspects of Semantic Structure (Cambridge 1990); Discourse and Cognition: Bridging the Gap (Stanford 1998); Grammar in Mind and Brain: Explorations in Cognitive Syntax (New York 1992) (до 27 \% названий);

- с неличными формами глагола: Comparing Partitions (J. of Classification 1985); Learning to Merge Word Senses (НД 2007); Measuring Historical Word Sense Variation (НД 2011); Learning Word Sense Distributions, Detecting Unattested Senses and Identifying Novel Senses Using Topic Models (Baltimore 2014) (до 7 \% названий);

- с вопросительным (по форме) предложением: Do Word Meanings Exist? (Patrick Hanks, 2000); How to do Philosophy with Words (JBs 2016) (до 3 \% названий);

- сочетающие перечисленные выше модели (до 34 \% названий): Metaphorical Models of Thought and Speech: A Comparison of Historical Direction and Metaphorical Mappings in the Two Domains (Berkley 1987); Article Structures: Moving from Printed to eDictionaries; English for Community Membership: Planning for Actual and Potential Needs (НД 2015).

В корпусе представлены и другие модели названий (менее $5 \%$ всех названий научных произведений на английском языке), ср.: Not all ambiguous words are created equal: An EEG Investigation of Homonymy and Polysemy (Brain and Language 2012); Kilgarriff, A. 'I don't believe in word senses' (Computers and the Humanities 1997).

В результате модели названий научных статей, докладов и книг, которые используются носителями английского языка, имеют простую и прозрачную структуру и благодаря этому оказываются легкими для восприятия и понимания. Наиболее типичными для (развернутого) заголовка научной статьи (книги, доклада и т. д.) на английском языке являются двухчастные структуры, состоящие из тематического (основного, «широкого», «исходного») компонента, стоящего вначале, и его рематических характеристик (дополнительных, «уточняющих»), часто следующих за двоеточием. Кроме того, двумя частями заголовка могут быть равноправные компоненты, а также главный и подчиненный, более общий и более узкий по значению, соединенные союзом and (или предлогом). В любом случае двухчастная структура заголовка (а также любого другого предложения) обеспечивает прозрачность его структуры и потому его легкое восприятие и понимание.

Так, упомянутое выше вполне стилистически нейтральное (для научной речи на русском языке) название научной статьи «O принщипе деления редуиированных гласных на сильные и слабые в позднем праславянском и древних славянских языках» (ВЯ) в самом журнале переведено на английский язык следующим образом (пословно): "On the principle of the division of reduced vowels into tense and weak in late Common Slavic and in Old Slavonic languages». Пословный перевод дает громоздкую конструкцию с повторяющимся и потому стилистически маркированным предлогом of и содержит абстрактную и отглагольную лексику, которая неоправданно удлиняет название. Такой перевод названия не соответствует научной речи на английском языке в целом и «устройству» и организации названий научных статей на нем в частности. $\mathrm{Cp}$. типичную для английского языка модель названия: Dividing reduced vowels... Она сокращает название, позволяет устранить малоинформативные или грамматически маркированные с точки зрения научной речи на английском языке выражения и конструкции (On the principle, повторы предлога of), делает заголовок менее формальным, более динамичным и «user-friendly» (дружественным для пользователя): простым для восприятия, выразительным, компактным, лаконичным и не содержащим (коммуникативно) избыточных компонентов.

4. В научной речи на русском и английском языках есть свои «ложные друзья переводчика», которые нередко встречаются в названиях научных статей или в сопровождающих их текстах (аннотации и др.). Так, почти курьезным недоразумением можно счи- 
тать использование при переводе названий научных докладов и статей с русского языка на английский созвучных друг другу аналогов типа аспект - aspect, перспектива perspective. Эти понятия используются в русском языке иначе, чем в английском [Рябцева, 2017]. Например, по-русски не говорят «в лингвистической (когнитивной, юридической, психологической) перспективе», а поанглийски говорят именно так, ср.: Applied Linguistics Perspectives on CLIL («Content and Language Integrated Learning») (JBs 2016). См. также «образцово-показательные» заголовки книг на английском языке: Similative and Equative Constructions: A Cross-linguistic Perspective (JBs 2017); Discourse, Grammar and Ideology: Functional and Cognitive Perspectives (London 2014).

Другой частой причиной порождения «ложных друзей переводчика» выступает желание выразить заданный в русском языке смысл наиболее близким «контекстно-независимым» эквивалентом, в результате чего происходит подмена понятий. Так, русск. особенности переводится на английский как ?peculiarities вместо естественного distinctions, свобода слова - как ?freedom of statement вместо устоявшегося freedom of speech, языковая личность - как ?linguistic personality или ?language personality, не используемые в научной лингвистической литературе на английском языке, и др. Примеры (неудачного) перевода названий научных докладов с русского на английский: «Лексические и стилистические особенности сказок Oскара Уайлда» - «Oscar Wilde’s Fairy Tales: Lexical and Stylistic Peculiarities», «Некоторые особенности функционирования лексем, обозначаюших полезные ископаемые в русском и английском языках» - «Sоте Peculiarities of Functioning of Terms which Denote Natural Resources in the Russian and English languages» (НД 2016), «Типологические особенности морфемной структуры слова в английском и бурятском языках» "Typological Peculiarities of Morphemic Structure of a Word in English and Buryat» («Урало-алтайские исследования»). Ср.: peculiarity - «a strange or unusual quality» (Longman Dictionary of Contemporary English Online) vs. особенность - «характерное, от- личительное свойство» (Russian-dictionaryOzhegov.htm).

Структура, организация, лексика и коммуникативная сущность названий научных статей, книг и докладов как особого «малого» жанра научного стиля, с одной стороны, постоянно изменяются, развиваются и становятся более унифицированными, причем в мировом масштабе, а с другой стороны, оставаясь доминантным компонентом научного текста, приобретают ряд не свойственных им черт (о них будет сказано ниже). Следует также отметить, что в названиях научных статей на русском языке (или в их переводах на английский язык) стала активно распространяться «международно признанная» конструкция с двоеточием. Она обеспечивает компактность названия, его «свернутость» и семантическую насыщенность, а также упорядоченность, структурированность и прозрачность. Ср. название статьи в ВЯ и его (в целом) удачный («не-пословный») эквивалент на английском языке: «Лингвистические проблемы упорядочения научно-технической терминолоzиu» - Unification of scientific and technical terminology: some linguistic problems (ВЯ). В исследовании И.С. Куликовой и Д.В. Салминой, посвященном эволюции названий в журнале «Вопросы языкознания», показано, что в названиях статей конструкция с двоеточием использовалась с 1952 по 1979 г. всего два раза, с 1980 по 1999 г. - 30 раз, а с 2000 по 2014 г. - уже 90 раз. Напротив, дополнительный компонент названия - (на материале) с 1980 по 1999 г. использовался 40 раз, а с 2000 по 2014 г. - всего 7 раз [Куликова, Салмина, 2015 , c. 43$]$.

\section{Принципы перевода названий научных статей \\ с русского языка на английский}

Типичные модели названий научных произведений на русском и английском языках, с одной стороны, демонстрируют различия в стиле научного мышления и изложения на этих языках, а с другой - показывают, что их пословный перевод с русского на английский в большинстве случаев приводит к нарушению стилистических норм научной речи на английском языке. В результате проведенного иссле- 
дования можно сформулировать краткие правила перевода названий научных статей, книг, докладов и т. д. с русского на английский язык (точнее, выражения заданного в заголовке на русском языке смысла средствами английского языка).

1. Заголовок по-английски не должен быть длинным и многословным, поэтому он может (и даже должен) быть короче, чем на русском языке. В названии на английском языке нежелательно использование широкозначной и малоинформативной лексики типа система, функция, роль, статус, проблема и т. п., а также любых отглагольных существительных (employment, development, systematization и др.), поскольку они требуют «генитивного» предлога $o f$, который, как и само отглагольное существительное, усложняет структуру заголовка. В (коротких) заголовках на английском языке желательно использовать такие предлоги, как in, on, for, from, to, across и т. п.

2. Содержание (развернутого) заголовка следует разбить на две равнозначные или неравнозначные части: тематическую и рематическую (основную и дополнительную); тема в названии должна предшествовать реме, ср.: "Semantic representation of the concept BLACK» vs. The Concept BLACK and its Semantic Representation. В заголовке, содержащем равнозначные части, желательно использовать союз and, например: Reflective Linguistics and the Study of Language (London 2015).

3. «Тема» (основная часть) заголовка может быть отделена от его рематической (дополнительной) части двоеточием. Материал, который в названии на русском языке помещен в скобки, желательно включить в название на английском языке без скобок. Сложные многокомпонентные заголовки можно разбивать последовательно на две части, соединяя их предлогами, союзами и двоеточием, ср.: Prescription and Tradition in Language: Establishing Standards across Time and Space (Multilingual Matters, 2016). Неполное соответствие заголовка на английском языке заголовку на русском не означает, что заголовок на русском языке следует изменить. Важно, чтобы оба заголовка звучали естественно и органично на своем языке и выражали один и тот же смысл. Ср. выделен- ные полужирным шрифтом элементы в названиях научных докладов на русском языке и их удачные английские эквиваленты: «Интертекстуальность и ее роль в совершенствовании процесса овладения иностранным языком»-Intertextuality and its Role in Foreign Language Acquisition Refinement, «Языковая игра в жанре британской кинорецензии» - Stylistic Devices in British Film Reviews (НД 2016).

\section{Заключение: инновации и перспективы}

Научная речь на русском языке значительно отличается от научной речи на английском языке не только в силу лингвистической (грамматической, лексической, семантической, прагматической и т. д.) асимметрии между языками, обусловленной асимметрией естественного языка в принципе [Рябцева, 2005, с. 9-25], но и ввиду различий в стиле мышления и коммуникации в данных культурах. Эти различия ярко проявляются в названиях научных произведений и свидетельствуют о том, что пословный перевод с русского языка на английский часто не соответствует стилистическим нормам научной речи на английском языке.

В целом можно сказать, что исследователи английского языка, в том числе и научной речи на английском языке, подчеркивают, что ему свойственны короткие, точные и простые слова и структуры, выразительность, отказ от абстрактной лексики, усложненных синтаксических конструкций и др. Научной речи на русском языке свойственны другие характеристики, отражающие в целом другой стиль мышления. Явно и ярко эти различия проявляются именно в названиях научных статей на этих языках. В связи с этим для передачи названия научной статьи, написанной (и озаглавленной) по-русски, нужно учитывать особенности построения названий научных произведений на английском языке. Пословный перевод, который часто используется в отечественных изданиях (в журналах, материалах конференций и др.), препятствует их главному предназначению - привлечь внимание международного научного сообщества к научным исследованиям, проводимым в нашей стране. 
Тем не менее в ряде российских научных изданий, требующих от авторов статей на русском языке аннотации и названия статьи на английском, встречается «не-пословный» перевод на английский язык, то есть перевод, передающий смысл средствами, типичными для названий на английском языке, имеющими соответствующую структуру, более компактный состав, более семантически конкретизированные компоненты и т. п. Можно привести следующие примеры названий научных докладов и их удачного (в целом) перевода на английский язык: «Лексические и стилистические особенности сказок Оскара Уайлда»-Oscar Wilde's Fairy Tales: Lexical and Stylistic Peculiarities, «Особенности языков эльфов в произведениях Дж.Р.Р. Толкина»-On English Languages Constructed by J.R.R. Tolkien, «Проблема использования послович и поговорок на уроках английского языка»-How Should Proverbs and Sayings be Dealt with in the Lessons of English? (НД 2016). Таким образом, культура оформления научных статей на русском языке, в первую очередь перевод их названий на английский язык, постепенно приближается к международному уровню, особенно благодаря отходу от пословного перевода.

Следует особо выделить тот факт, что в названиях научных статей как на русском, так и на английском языках все чаще используются такие креативные стилистические приемы, как игра слов, употребление иронического или шутливого выражения или неожиданной цитаты, прецедентного «текста», метафорическое и т. п. переосмысление понятий, а также более тонкие стилистические и своего рода эстетические приемы, придающие заголовку, в том числе и научному, особую «аттрактивность» [Филоненко, 2008]. Пословный перевод в таких случаях исключен уже хотя бы потому, что для русского языка предпочтительно эксплицитное выражение смысла, тогда как английский язык выработал специальные средства компрессии и «сжатия» текста. Так, одна из представительных конференций по прикладной лингвистике, которая проходила в США в 2015 г., называлась «коротко и ясно»: «Applied Linguistics Applied». Эта остроумная и почти непереводимая игра слов тем не менее может быть выражена и по-рус- ски. Ср. также «нетипичные» для научного стиля экспрессивно маркированные названия книг, статей и докладов: Brookes I. Painting the Forth Bridge: Coping with Obsolescence in a Monolingual English Dictionary (2004); Crystal D. Txtng: The Gr8 Db8. (2008); C. L. Cameron. The Discourse Dynamics Approach to Verbal Metaphor: Model and Method; Haque M. Ch. Discourse Patterns in Educational Ads: (Un)social Practices (НД 2014); О.А. Гусева. «Коммуникативно значимый ... смех»; А.В. Кремнева. «Всякий ли текст мечтает стать прецедентным?»; Н.М. Перельгут, О.Я. Яковишак. «Эволюиия и революиия в научном дискурсе?»; Е.В. Федорова. "“Метафизический пластилин”, или концептуальная интеграция как способность создавать новые смысль в критическом дискурсе» (НД 2014).

Здесь необходимо указать еще на одну важную особенность научного языка, стиля и мышления, проявляющуюся в названиях научных статей и имеющую непосредственное отношение и к научному познанию, и к его осмыслению. Это интеграция рационального, эмоционального и эстетического в интерпретации получаемых новых научных знаний в виде особо экспрессивных понятий и терминов. Сочетание рационального и эмоционального в научной терминологии прослеживается как в традиционно приводимых в целях его демонстрации примерах из физики, астрономии и других точных наук (ср.: звезда-карлик, заторможенная частица), так и во множестве новых научных понятий и терминов, которые предлагает современная наука, чувствующая свою связь не только с созданием или обнаружением нового, но и с творчеством, культурой, эмоциональной сферой и эстетикой, равно как и творчество стало осмыслять себя как особый эстетический язык: «Современное искусство стало базировать свои принципы на языковых играх и лингвистических постулатах» [Фещенко, 2016, с. 62].

Например, целый ряд современных лингвистических терминов имеет экспрессивный характер, содержит в своем значении явные и неявные эмоционально значимые и эмоционально-образные компоненты и аксиологически маркированные элементы [Котюрова, Соловьева, 2017, с. 33]. Особенно ярко интегра- 
ция рационального, эмоционального и эстетического, их синкретичное выражение воплощается в авторских номинациях и терминах [Табанакова, 2016, с. 89], которые часто используются и в названиях научных статей: «Автономизмус, социализмус и идиотизмус: европеизмы в иврите, 1917-1918», "Немечкие “языковые острова” в Алтайском крае», «Эгоцентрические валентности и деконструкция говорящего», «Ироническая грамматика: средний род в игровой неологии» (ВЯ); а также терминологический диссонанс, ложноориентирующие терминь-фантомы, ономастический миф, мифоэпоним и название статьи «Мифоэпонимы в зеркале кросспрофессионального анкетирования» [Васильева, Тритенко, 2017]. Проблема перевода таких названий с русского на английский требует отдельного изучения [Иоанесян, 2016; Табанакова, 2013]. Однако следует отметить, что в современных исследованиях, в том числе когнитивных, подчеркивается возрастающая роль эстетического компонента во всех типах и видах коммуникации, включая научную, в частности, в связи с расширяющимися возможностями цифровых технологий в представлении разнообразной информации, особенно в виде ярких, наглядных и выразительных изображений, таблиц, графиков, диаграмм, с применением разнообразных шрифтов и других семиотических средств.

В заключение следует отметить, что, используя «доминантные», как сейчас говорят, модели названий научных статей на английском языке, участник международной научной конференции или автор, публикующийся в международном научном журнале, имеет возможность названием своей научной работы, не только традиционно оформленным, но и «инновационным», привлечь внимание своих коллег из других стран и вызвать их интерес к проведенному исследованию, а также быть правильно ими понятым и по достоинству оцененным.

В качестве теоретической интерпретации полученных данных можно сказать, что в статье затрагивается одна из актуальных проблем когнитивной лингвистики и «интегративного переводоведения» одновременно (ср.: [Болдырев, 2016; Поликарпов, 2017]). Она заключается в изучении отражения в стиле мыш- ления структуры языка, с одной стороны, и в установлении связи между устройством языка и его культурными коммуникативными моделями, которые обязательно должны учитываться в процессе перевода с языка на язык, - с другой.

\section{ПРИМЕЧАНИЕ}

${ }^{1}$ Работа выполнена частично при финансовой поддержке РФФИ, грант 18-012-00736 А «Интегральное представление эмоциональной сферы человека (на материале лексики и фразеологии славянских, романских, германских, кельтских и финно-угорских языков)».

\section{СПИСОК ЛИТЕРАТУРЫ}

Бахтин М. М., 1979. Проблема речевых жанров // Эстетика словесного творчества. М. : Наука. C. 259-295.

Болдырев Н. Н., 2016. Язык и структура сознания // Когнитивные исследования языка. Вып. XXIV. C. $35-48$.

Брежнева Д. Д., 2017. Языковая игра в жанре британской кинорецензии // Актуальные проблемы лингвистики, переводоведения, литературоведения, лексикографии, теории и практики обучения иностранным языкам (к юбилею Дж.Р.Р. Толкина) : сб. материалов Междунар. науч. конф. М. : МГОУ. С. 51-53.

Васильева Н. В., Тритенко Т. В., 2017. Мифоэпонимы в зеркале кросспрофессионального анкетирования // Межкультурная $\leftrightarrow$ интракультурная коммуникация: прецедентный текст в коммуникации : материалы VI Междунар. науч.-практ. конф. Уфа : БашГУ. С. 127-131.

Иоанесян Е. Р., 2016. Лексические трансформации при переводе // Научный диалог. № 3 (51). C. $29-41$.

Костомаров В. Г., 1965. Из наблюдений за языком газеты: газетные заголовки // Из опыта преподавания русского языка нерусским. М. : Мысль. С. 163-168.

Котюрова М. П., 2016. Об эталонном научном тексте // Стереотипность и творчество в тексте. Пермь : Перм. гос. ун-т. Вып. 20. С. 63-71.

Котюрова М. П., Баженова Е. А., 2007. Культура научной речи: текст и его редактирование. Пермь : Пермский гос. ун-т. 282 с.

Котюрова М. П., Соловьева Н. В., 2017. Современный научный текст (сквозь призму дискурсивных изменений). Пермь : Пермский гос. ун-т. 204 c. 
Куликова И. С., Салмина Д. В., 2015. Заголовок научной статьи как речевой жанр // Международный научный институт «Educatio». № 3 (10). С. 41-44.

Меньшакова Н. Н., 2016. Трансляция наукообразности в студенческих переводах с русского языка на английский // Индустрия перевода : материалы VIII Междунар. науч. конф. (Пермь, 6-8 июня 2016 г.). Пермь : Пермский нац. исслед. политех. ун-т. Т. 1. С. 110-114.

Поликарпов А. М., 2017. Интегративное переводоведение: предпосылки возникновения и основные идеи // Вестник Волгоградского государственного университета. Серия 2, Языкознание. Т. 16, № 3. C. 6-17. DOI: https://doi.org/ 10.15688/jvolsu2.2017.3.1.

Рябцева Н. К., 2005. Язык и естественный интеллект. M. : Academia. $640 \mathrm{c}$.

Рябцева Н. К., 2017. Иностранный язык для академических целей: интегральное представление лингвистической информации // Магия ИННО: новые измерения в лингвистике и лингводидактике : материалы III Междунар. науч.практ. конф. В 2 т. М. : МГИМО - Университет. T. 2. C. 243-250. URL: http://inno-conf. mgimo.ru/i/inno-magic-2017 tom-2.pdf.

Табанакова В. Д., 2013. Авторский термин: знаю, интерпретирую, перевожу. Тюмень : Изд-во Тюмен. гос. ун-та. 208 с.

Табанакова В. Д., 2016. Предикативный потенциал заголовка научного текста // Стереотипность и творчество в тексте. Пермь : Перм. гос. ун-т. Вып. 20. С. 85-93.

Фещенко В. В., 2016. Искусство как язык, язык как искусство: терминологический и концептуальный трансфер // Труды Института русского языка им. В.В. Виноградова. № 7. С. 49-69.

Филоненко Т. А., 2008. Аттрактивные заголовки в научной речи // Известия Самарского научного центра Российской академии наук. «Педагогика и психология». «Филология и искусствоведение». № 2. С. 290-296.

McCarthy M., O’Dell F., 2012. Academic Vocabulary in Use. Cambridge : Cambridge University Press. $176 \mathrm{p}$.

Riabtseva N. K., 1988. Conceptual Background for Interlinguistic Interference // Interferenz in der Translation: «Übersetzungswissenschaftliche Beiträge». Leipzig : VEB Verlag Enzyklopadie. S. 88-92.

Riabtseva N. K., 2013. English for Scientific Purposes. $6^{\text {th }}$ ed. M. : Nauka-Flinta. 598 p.

Swales J. M., Feak Ch. B., 2010. B. English in Today's Research World. A Writing Guide. Michigan : The University of Michigan Press. 304 p.
Wallwork A., 2011. English for Writing Research Papers. N. Y. ; Dordrecht ; Heidelberg ; London : Springer. $347 \mathrm{p}$

\section{REFERENCES}

Bakhtin M.M., 1979. The problem of speech genres. Bakhtin M.M., ed. Estetika slovesnogo tvorchestva. Moscow, Nauka Publ., pp. 259-295.

Boldyrev N.N., 2016. Language and the structure of consciousness. Kognitivnye issledovaniya yazyka, no. 24, pp. 35-48.

Brezhneva D.D., 2017. Stylistic devices in British film reviews. Aktualnye problemy lingvistiki, perevodovedeniya, literaturovedeniya, leksikografii, teorii i praktiki obucheniya inostrannym yazykam (k yubileyu Dzh.R.R. Tolkina): sbornik materialov Mezhdunarodnoy nauchnoy konferentsii. Moscow, MGOU Publ., pp. 51-53.

Vasilyeva N.V., Tritenko T.V., 2017. Myth eponims as reflected in cross-professional questionnaire. Mezhkulturnaya $\leftrightarrow$ intrakulturnaya kommunikatsiya: pretsedentnyy tekst $v$ kommunikatsii: materialy VI Mezhdunarodnoy nauchno-prakticheskoy konferentsii. Ufa, BashGU Publ., 2017, pp. 127-131.

Ioanesyan E.R., 2016. Lexical transformations in translation. Nauchnyy dialog [Scientific Dialogue], no. 3 (51), pp. 29-41.

Kostomarov V.G., 1965. On the newspaper discourse: titles. Iz opyta prepodavaniya russkogo yazyka nerusskim. Moscow, Mysl Publ., pp. 163-168.

Kotyurova M.P., 2016. On sample academic text. Stereotipnost i tvorchestvo v tekste. Perm, Perm. gos. un-t Publ., iss. 20, pp. 63-71.

Kotyurova M.P., Bazhenova E.A., 2007. The culture of academic writing: text and the process of its editing. Perm, Perm. gos. un-t Publ. 282 p.

Kotyurova M.P., Solovyeva N.V., 2017. Modern academic text (in the light of discursive changes). Perm, Perm. gos. un-t Publ. 204 p.

Kulikova I.S., Salmina D.V., 2015. Titles of academic papers as a speech genre. Mezhdunarodnyy nauchnyy institut «Educatio», no. 3 (10), pp. 41-44.

Menshakova N.N., 2016. Transmitting scientism in Russian-English translations performed by students. Industriya perevoda: materialy VIII Mezhdunar. nauch. konf. (Perm, 6-8 iyunya 2016 g.). Perm, Permskiy nats. issled. politekh. un-t., vol. 1, pp. 110-114.

Polikarpov A.M., 2017. Integrated translation studies: origin and main ideas. Vestnik Volgogradskogo gosudarstvennogo universiteta. Seriya 2, 
Yazykoznanie [Science Journal of Volgograd State University. Linguistics], vol. 16, no. 3, pp. 6-17. DOI: https://doi.org/10.15688/jvolsu2. 2017.3.1.

Ryabtseva N.K., 2005. Natural language and human intelligence. Moscow, Academia Publ. 640 p.

Ryabtseva N.K., 2017. Foreign language for academic purposes: integrated presentation of linguistic information. Magiya INNO: Novye izmereniya $v$ lingvistike i lingvodidaktike: materialy III mezhdunarodnoy konferentsii. Moscow, MGIMO Publ., vol. 2, pp. 243-250. URL: http:// inno-conf.mgimo.ru/i/inno-magic-2017_tom2.pdf.

Tabanakova V.D., 2013. The author's term: I identify, interpret, and translate it. Tyumen, Izd-vo Tyumen. gos. un-ta. 208 p.

Tabanakova V.D., 2016. Academic paper titles and their predicative potential. Stereotipnost $i$ tvorchestvo v tekste. Perm, Perm. gos. un-t Publ., vol. 20, pp. 85-93.

Feshchenko V.V., 2016. Language as art, art as language: a terminological and conceptual transfer. Trudy Instituta russkogo yazyka im. V.V. Vinogradova [Proceedings of the V.V. Vinogradov Russian Language Institute], no. 7, pp. 49-69.

Filonenko T.A., 2008. Attractive titles in academic discourse. Izvestiya Samarskogo nauchnogo tsentra Rossiyskoy akademii nauk. «Pedagogika i psikhologiya». "Filologiya $i$ iskusstvovedenie», no. 2, pp. 290-296.

McCarthy M., O’Dell F., 2012. Academic Vocabulary in Use. Cambridge, Cambridge University Press. $176 \mathrm{p}$.

Ryabtseva N.K., 1988. Conceptual Background for Interlinguistic Interference. Interferenz in der Translation: «Übersetzungswissenschaftliche Beiträge». Leipzig, VEB Verlag Enzyklopadie, pp. 88-92.

Ryabtseva N.K., 2013. English for Scientific Purposes. 6th ed. Moscow, Nauka-Flinta Publ. 598 p.

Swales J. M., Feak Ch. B., 2010. B. English in Today's Research World. A Writing Guide. Michigan, The University of Michigan Press. 304 p.

Wallwork A., 2011. English for Writing Research Papers. N.Y.; Dordrecht; Heidelberg; London, Springer. $347 \mathrm{p}$.

\section{Information about the Author}

Nadezhda K. Ryabtseva, Doctor of Sciences (Philology), Head of Department of Applied Linguistics, Institute of Linguistics, Russian Academy of Sciences, Bolshoy Kislovskiy St., 1, bld. 1, 125009 Moscow, Russia,nadia_riabceva@mail.ru,https://orcid.org/0000-0002-2042-4615

\section{Информация об авторе}

Надежда Константиновна Рябцева, доктор филологических наук, заведующая сектором прикладного языкознания, Институт языкознания РАН, Большой Кисловский, 1, стр. 1, 125009 г. Москва, Россия, nadia_riabceva@mail.ru, https://orcid.org/0000-0002-2042-4615 